\title{
Progressive rehabilitation - Martabe Gold Mine as a case study
}

\author{
S Pearce O'Kane Consultants, UK \\ M Orr G-Resources, Indonesia \\ K Grohs G-Resources, Indonesia \\ J Pearce O'Kane Consultants, Australia
}

\begin{abstract}
Progressive rehabilitation has been recognised by the mining industry as a key strategy for minimising mine closure costs and environmental risk, with the rehabilitation of potentially acid-forming waste rock being of particular interest due to the very large liabilities associated with sites where this risk has not been properly addressed. When properly implemented as an engineered solution, progressive rehabilitation of potentially acid-forming waste rock can provide an inherently more robust and lower risk rehabilitation strategy compared with the commonly-implemented alternative of an end-of-life waste dump covers.
\end{abstract}

A case study is presented herein where progressive rehabilitation of potentially acid-forming waste rock has been successfully integrated with ongoing construction of the embankment of a tailings storage facility (TSF). The mine site in question, the Martabe Gold Mine in Indonesia, is thought to be unique in that construction of the TSF embankment at the site will require utilisation of almost all of the waste rock to be produced life-of-mine. The TSF embankment is therefore a fully integrated and engineered structure addressing both tailings and waste rock disposal requirements for the site. This approach offers a number of key benefits, including minimisation of both waste rock rehabilitation and tailings storage costs, and minimising the risk of long-term acid mine drainage.

The progressive mine waste rehabilitation strategy adopted by G-Resources at the Martabe Gold Mine was designed taking into account the inherent properties of the waste rock materials, the run-of-mine waste rock schedule, and the engineering constraints required in order to construct a TSF embankment to exacting geotechnical standards. The strategy has required systematic implementation of outcomes reflective of industry leading practice, including:

- Detailed waste characterisation studies.

- Development of waste characterisation criteria.

- Production of a life-of-mine waste schedule.

- Selection of a waste sealing specification based on oxidation modelling.

- Progressive implementation of selective waste placement and sealing.

- Performance measurement to validate design and implementation.

All key technical teams at the Martabe Gold Mine, including exploration, mine geology, mine planning, TSF construction and environment, have played an integral role in the implementation of this strategy, which can be described as an integrated waste management solution in which minimisation of mine closure risk is process that is carried out across the life of the mine. 


\section{Introduction: progressive management in context}

Acid and metalliferous drainage (AMD) is arguably the most significant environmental liability resulting from mining worldwide. In the 1990s, global management costs for AMD were estimated to be approximately AUD 2.1 billion per annum (Harries 1997). In 2003, the total worldwide acid mine drainage liability for both historic and operational mines was estimated to be in excess of AUD 14 billion (Lottermoser 2003).

There are a number of key factors that have resulted in these AMD liabilities being created at mine sites.

Firstly, the obvious visual and chemical symptoms of uncontrolled AMD may take many years to reveal themselves. As a result it may be difficult to confirm with confidence the success of site rehabilitation until well after mine closure, at which stage there may be no company funds remaining for rectification works. There are a number of well-known legacy mine sites that initially demonstrated apparent rehabilitation success followed by dramatic long-term failure.

Secondly, in the planning stages of a mining project, fundamental decisions may be made in relation to waste rock management, for example, conceptual dump design, prior to implementation of the detailed assessments and planning required to validate these decisions. A consequence of this design before facts approach is that retrofitting of AMD mitigation strategies may be done later in the life of the mine, with fewer rehabilitation options available given that the mine waste stream has largely been placed in final position.

Thirdly, the methods for successful management of acid mine drainage are still arguably under development and not always widely understood across the mining industry, and there are few if any long-term case studies of sites where successful controls have been implemented into closure.

These factors have contributed to a proliferation of end-of-life strategies for the rehabilitation of potentially acid forming (PAF) waste rock dumps (WRDs), such as complex multi-layer final cover systems. This approach may place heavy reliance on the performance of an untested cover system, the robustness of such a system, over time, and even the availability of suitable materials to construct the system at mine closure.

Less common are strategies that have allowed for progressive rehabilitation of PAF waste rock during mining operations. Even where progressive capping or sealing solutions have been implemented, these have commonly involved the placement of potentially acid forming materials in non-engineered cells within waste dumps, in an effort to isolate them, but without the use of oxidation modelling or comparative studies to validate the configuration.

Given the uncertainties around cover performance and long-term durability, a reliance on final untested cover systems and non-engineered PAF cells cannot be upheld as examples of robust risk management though engineering design. The primary design consideration for the storage of PAF material should be based on the international principals of risk management, grounded in the accepted view that prevention is better than mitigation. Cover systems and PAF cells in many cases do not meet this most basic principal (Pearce 2014).

Non-engineered PAF cells within waste dumps are commonly perceived as providing a degree of isolation for the contained material. A common term used in industry for this approach is waste 'encapsulation', however this terminology may be misleading as it implies a degree of engineered containment that is usually absent. Typically PAF cells are merely buried waste masses that rely on other engineered features such as final cover systems and drainage. This is to say they provide no protection against AMD in their own right.

Engineered cover designs with many years of demonstrated field performance have been implemented at a number of sites so reliance on a final engineered cover system may be the best solution available in some cases. However, the most vulnerable and most common failure point on a WRD is at the surface due to direct interaction with the environment (Pearce 2014). As a result, a design that solely relies on a final cover system can be said to be inherently less robust with respect to safety in design compared to alternatives that utilise progressively implemented containment systems such as layered options (discussed herein). 
This paper outlines a case study where the approach to designing and constructing an integrated waste rock landform has been based on a comprehensive understanding of the geochemical and geophysical properties of waste rock, the life-of-mine (LOM) waste schedule, modelled performance of compacted sealing layers and integration within the construction plan of a tailings storage facility (TSF) embankment. The physical and geochemical properties of the waste rock, and interrelationships of key properties, including reactivity, hydraulic conductivity and moisture-holding capacity is discussed.

The scope of this paper extends to the benefits of numerical modelling to provide a comprehensive understanding of the performance of different available sealing layer configurations in controlling AMD generation within the structure. Table 1 lists the acronyms used in this paper.

Table 1 Nomenclature used in this paper

\begin{tabular}{cl|cl}
\hline ABA & Acid-base accounting & PAF/LAG & PAF (time lag to AMD generation onset) \\
\hline AMD & Acid and/or metalliferous drainage & PEM & Progressive encapsulation method \\
\hline ANC & Acid neutralisation capacity & ROM & Run-of-mine \\
\hline LOM & Life-of-mine & TSF & Tailings storage facility \\
\hline NAF & Non-acid forming & WRD & Waste rock dump \\
\hline NAPP & Net acid production potential & WRSF & Waste rock storage facility \\
\hline PAF & Potentially acid forming & & \\
\hline
\end{tabular}

\section{$2 \quad$ Martabe Gold Mine site}

The Martabe Gold Mine is owned and operated by G-Resources Group Limited and is located in the sub-district of Batangtoru, North Sumatra. Similar to other mines in tropical regions, local communities and high biodiversity value tropical forest are within close proximity to the mine site. The waterways that drain the site are important to the local communities as they use these waterways as a source of water for washing and cooking. Therefore, in order for the Martabe Gold Mine to be successful in this region, its ability to maintain its 'social licence to operate' is critical, and a key contributor to this is environmental performance.

The Martabe Gold mine is an open pit operation and commenced production in 2012. Based on current ore reserves, mine life is a minimum of ten years. The site has an integrated TSF that incorporates its WRD into the embankment of the TSF, which is a valley-fill containment structure.

The Martabe deposit comprises of a fairly complex local geology that contains a package of altered volcanics. Generally mineralised quartz veins (that contain high grade sulphide ore) cut through a package of volcanics that include various altered breccias and more competent andesite rock. Mineralisation types, include: shallow oxide materials, argillic, advanced argillic, and silicified material (mainly at depth). Mineralogical analysis and ABA identified acid generating minerals pyrite, jarosite and alunite. Gypsum, calcite and ankerite (the latter two being calcium carbonate based buffering minerals) are other key minerals identified that influence acid-base accounting interpretations.

As a result of the complex geology, mineralogy and thus geochemistry, a key focus for mine planning has been waste rock modelling and scheduling, as a required input to selective waste placement within the TSF embankment. 


\subsection{Waste rock management plan}

Key objectives for the site in regard to the management of AMD are:

- Progressive encapsulation of all PAF waste rock within the TSF embankment such that oxidation rates are controlled during construction and reduced to very low levels after the structure is completed.

- As a consequence of controlled oxidation rates, protection of downstream water quality in the long term after closure.

- Maximising the use of ROM waste for construction of the required sealing layers with minimum requirement for waste rehandling or use of construction materials sourced from borrow pits.

- Provision of a stable final surface that enables the achievement of rehabilitation targets in the long term after closure.

- Achieving these outcomes without compromising the geotechnical performance of the TSF embankment or provision of tailings storage capacity.

- Development of methods and systems that facilitate the successful management of AMD through continuous improvement over the life of the mine.

A detailed waste rock management strategy and AMD management technical manual has been developed by the authors and the Martabe Gold mine technical teams (including exploration, mine geology, exploration, mine planning, TSF). The technical manual documents:

- Technical guidance for specific aspects of waste rock management during the development and operational phases.

- An overall framework for the management of waste materials during the construction of the tailings storage facility.

Flow charts have been prepared to summarise the AMD management process and workflows (Figure 1). 


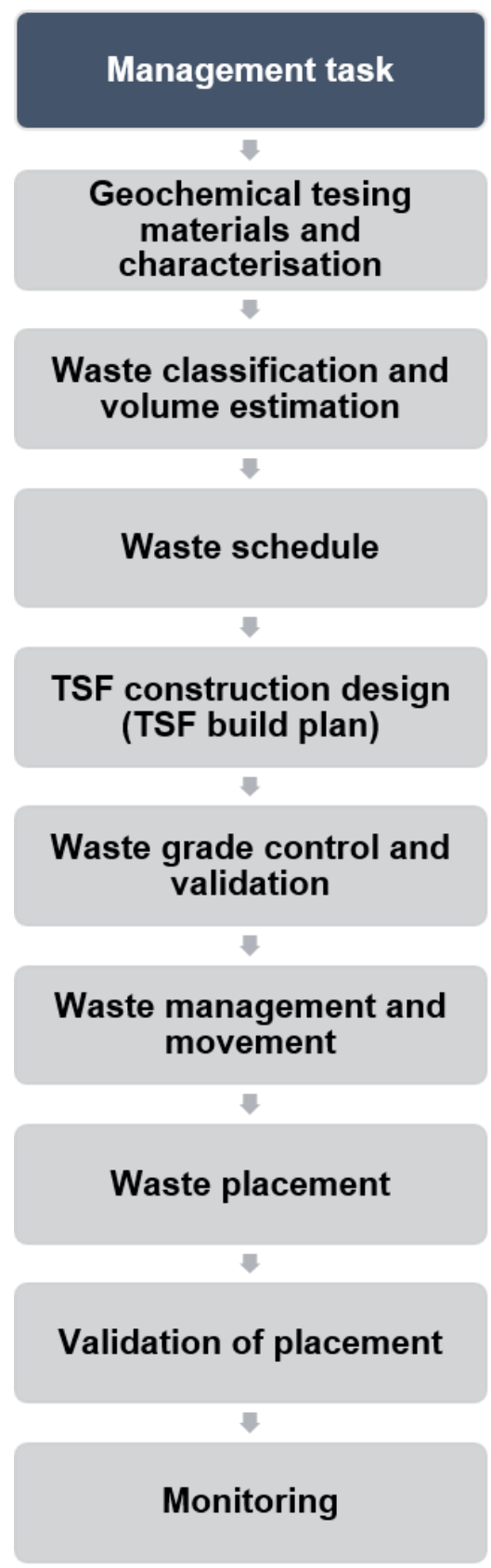

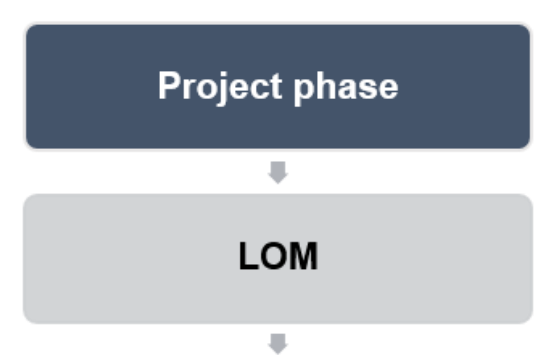
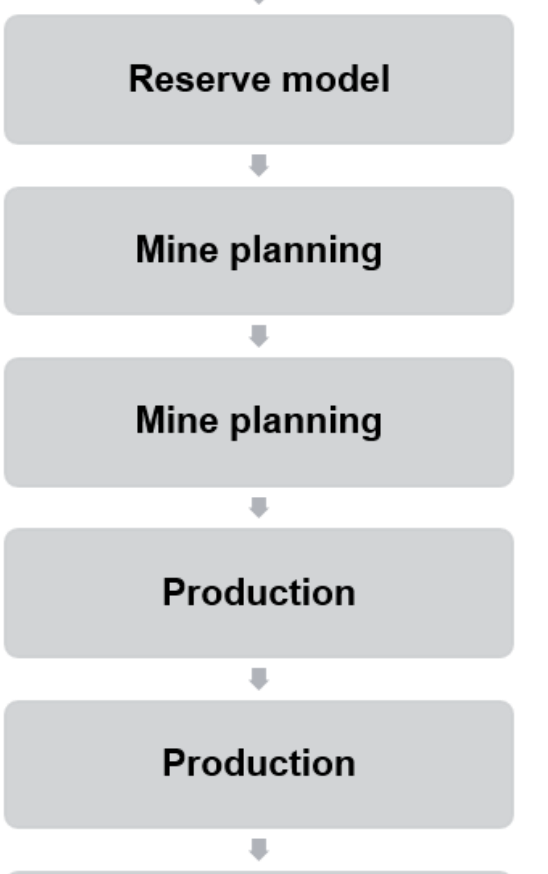

TSF construction

$\sqrt{2}$

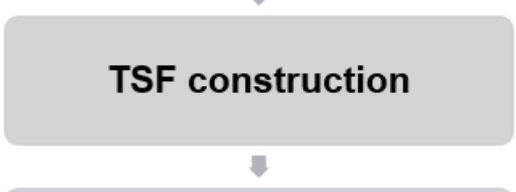

During/post construction

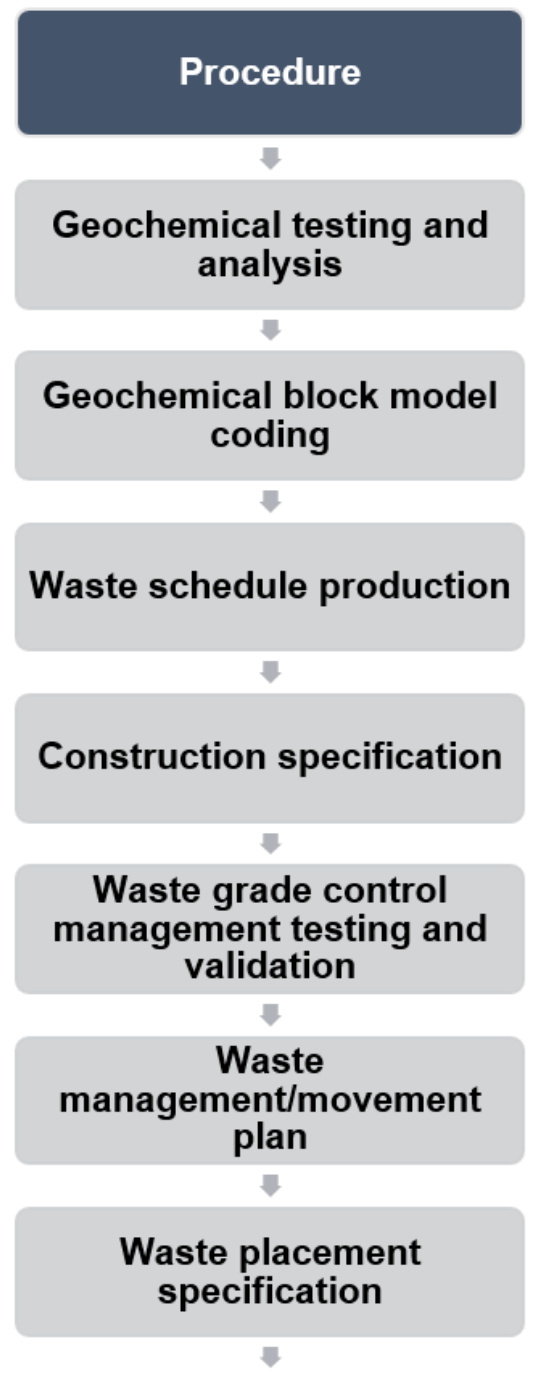

Placement QA/QC and validation

\section{Installation design implementation and monitoring plan}

Figure 1 Waste Rock Management Plan Framework at Martabe

\subsection{Geochemical classification program}

The geological and geochemical database developed by G-Resources for the Martabe Gold Mine is very extensive by the standards of other equivalent mines and can be regarded as an example of industry best-practice. Several sources of geochemical data were utilised to develop a risk-based classification methodology for operational use in classifying blocks of waste rock (Table 2). 
Table 2 Geochemical data sources used at the Martabe Gold Mine for development of the waste classification process protocol

\begin{tabular}{|l|l|}
\hline Geochemical data source & Samples \\
\hline Resource assay database & $\begin{array}{l}>10,000 \text { datapoints for total sulphur, sulphide sulphur, and calcium } \\
\text { content, base metals (As, Cu etc). }\end{array}$ \\
\hline Phase 1 geochemical testing & $\begin{array}{l}\text { Hundreds of samples analysed for acid ABA (sulphur speciation and } \\
\text { ANC), NAG, and paste } \mathrm{pH} .\end{array}$ \\
\hline Phase 2 detailed testing & $\begin{array}{l}\text { Range of detailed laboratory analyses, including total elemental analysis, } \\
\text { (stored) acidic salt analysis, mineralogical analysis, static leach testing, } \\
\text { kinetic NAG testing (KNAG), and acid buffering characteristic curves. }\end{array}$ \\
\hline Large scale leach columns & $\begin{array}{l}\text { In operation at site for }>10 \text { years and are thought to provide some of the } \\
\text { longest running kinetic data sets in the industry. }\end{array}$ \\
\hline
\end{tabular}

The waste classification system must take into account characteristics important for selective handling and treatment of waste rock under the chosen rehabilitation strategy. At the Martabe Gold Mine the key characteristics were determined to be:

- Predicted AMD risk.

- Potential acidity buffering potential (presence of carbonates such as calcite).

- Potential utility for use in construction (soft materials are more amenable to compaction for example).

The geochemical classification system is described in detail in Pearce (2015) and summarised in Table 3.

Table 3 Waste classification system developed for Purnama Pit at the Martabe Gold Mine

\begin{tabular}{ccccc}
\hline \multirow{2}{*}{$\begin{array}{c}\text { Waste } \\
\text { class }\end{array}$} & Name & \multicolumn{3}{c}{ Criteria } \\
\cline { 3 - 5 } & & NAPP $\left(\mathrm{kg} \mathrm{H}_{2} \mathrm{SO}_{4} / \mathrm{t}\right)$ & $\begin{array}{c}\text { Calcium } \\
(\mathbf{w t} \%)\end{array}$ & $\begin{array}{c}\text { Sub-code for } \\
\text { scheduling purposes }\end{array}$ \\
\hline 1 & NAF & $<0$ & Hard/soft \\
\hline 2 & PAF low sulphur & $0-5$ & Hard/soft \\
\hline 3 & PAF medium sulphur & $5-90$ & None \\
\hline 4 & PAF high sulphur & $>90$ & None \\
\hline 5 & PAF/LAG & $<90$ & $>0.4$ & Hard/soft \\
\hline
\end{tabular}

Predicted AMD risk is based on conventional NAPP criteria. NAPP values are calculated from assay data already available within the site's drill hole database. Maximum potential acidity is derived from $\% \mathrm{~S}$ content, and the ANC is derived from \% Ca (assumed to be calcite). A sub-code is indicated in the classification table to describe potential for compaction, i.e. hard-soft, for scheduling purposes. This is proposed as a means to account for the fact that softer materials should be preferentially used in the construction of internal sealing layers. This assessment is important at the scheduling stage.

The output from the waste block model using this approach is shown in Figure 2 . 


\section{Internal waste}

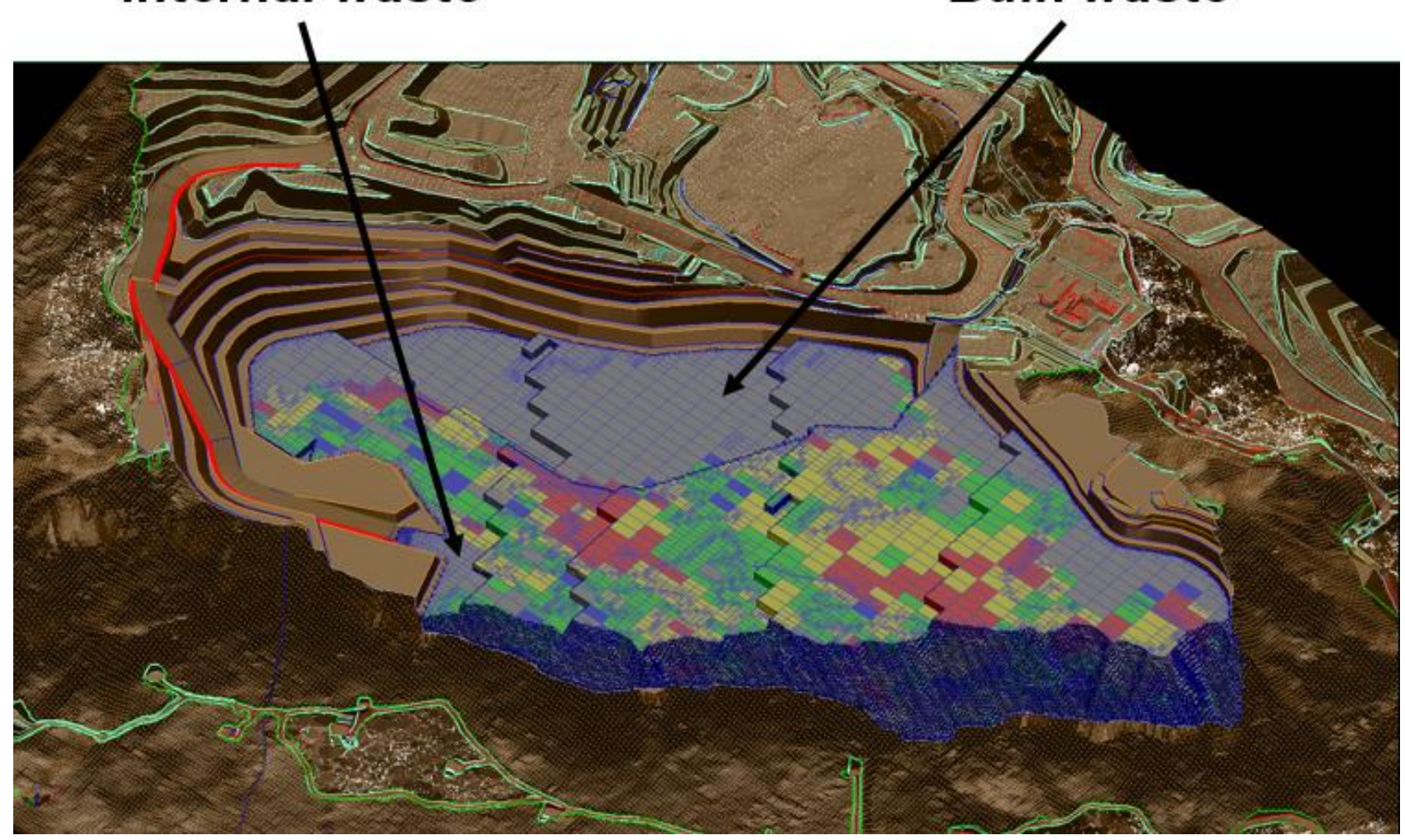

Figure 2 Waste rock block model output

\subsection{Waste rock schedule}

To reliably implement selective waste placement within the TSF embankment based on the criteria in Table 3, it is necessary to develop and plan around a waste rock schedule. The use of the waste rock schedule to inform planning decisions has been demonstrated by the author in previous publications (Pearce et al. 2012).

To produce a waste schedule, the mine areas are divided into benches or blocks. These are run through the waste block model to determine the volumes of NAF, PAF (low sulphur), PAF (medium sulphur), PAF (high sulphur) and PAF/LAG in each block, as it presents in the mining sequence, along with an estimate of compactability.

This schedule of overburden is then incorporated into the construction sequence and schedule, on which the short term dig/dump plans are based. This is shown schematically in Figure 3.

A LOM schedule is important to determine the availability of different materials used in construction of the structure, especially the availability of material suitable for construction of the sealing layers. 
LOM pit, block bench design

Mining sequence and schedule

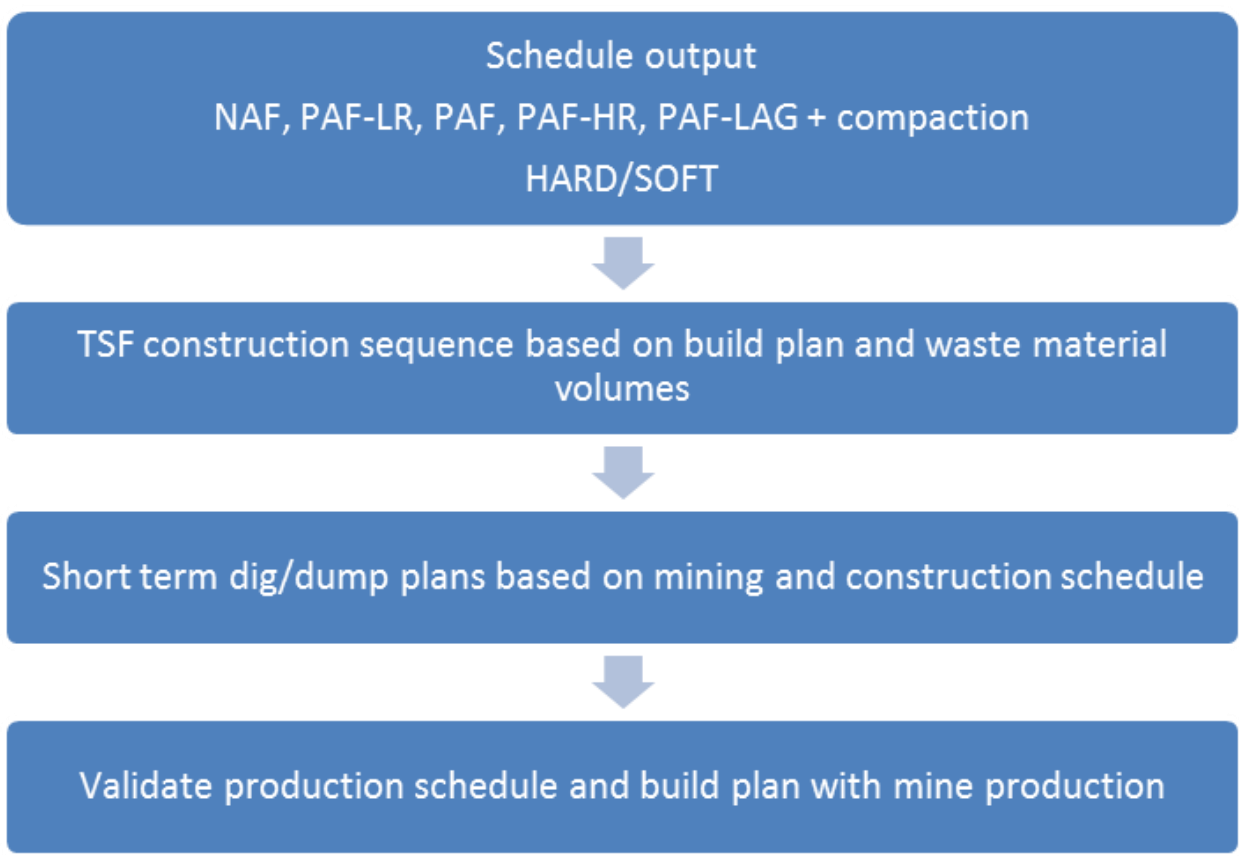

Figure 3 Waste rock schedule

\section{Control of oxygen ingress by means of progressive encapsulation}

\subsection{Progressive encapsulation}

A key feature of the waste sealing strategy being implemented at the site is that PAF is progressively encapsulated during the construction period. Figure 4 is a diagrammatic representation of this approach, with PAF waste being progressively encapsulated during construction on a lift by lift basis by the construction of piggyback layers of sealing material such that the PAF is enclosed in three dimensions. The method is progressive in that each sealing layer forms a de facto cover system for each lift that is constructed.

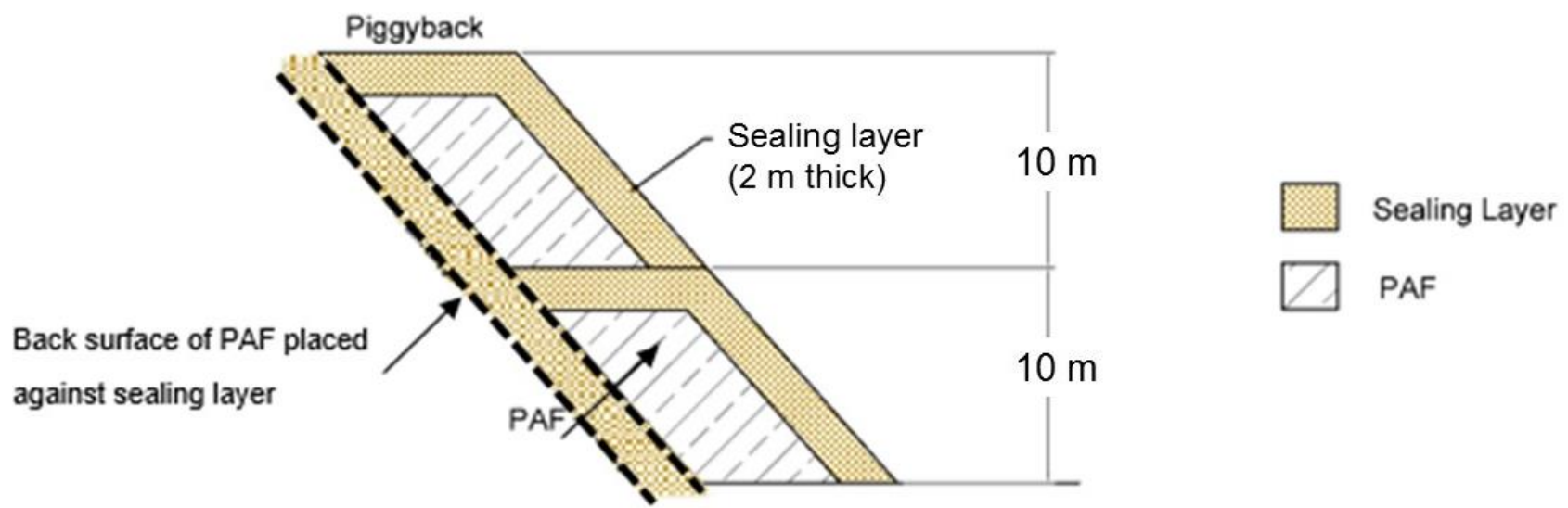

Figure 4 Design used as basis for modelling assessment 
The conceptual model for oxygen movement into the TSF embankment assumes that oxygen availability will be controlled by diffusion rather than advection. This assumption has been validated by numerical modelling (Section 3.2). Minimising entry of oxygen by diffusion will limit sulphide oxidation rates within the structure, in turn controlling the amount of AMD eventually leaving the structure. Proactively limiting oxygen availability to PAF waste rock is considered to be best practice in regards to managing AMD.

Because of the site's relatively high and consistent rainfall (leading to high infiltration rates) combined with the selective placement of finer-textured materials in the sealing layers, at some combination(s) of particle size distribution, water holding capacity, and surface infiltration rate, the sealing layer materials will maintain a sufficiently high degree of saturation to limit oxygen ingress due to diffusion and transport via water percolation.

Sophisticated computer simulations were used to examine the two-dimensional nature of oxygen ingress into sealed zones (Figure 5). These simulations examined a range of saturated hydraulic conductivity ( $\mathrm{k}_{\text {sat }}$ ) values for the sealing material, as well as lower and higher values for runoff. For areas near the middle of the zone, transport of water and oxygen will essentially be one-dimensional; however, near the outer wall of the final landform, ingress from the sidewalls could be a substantial component of the total oxygen ingress, as materials placed on the outer walls are unlikely to have the same consistency of compaction.

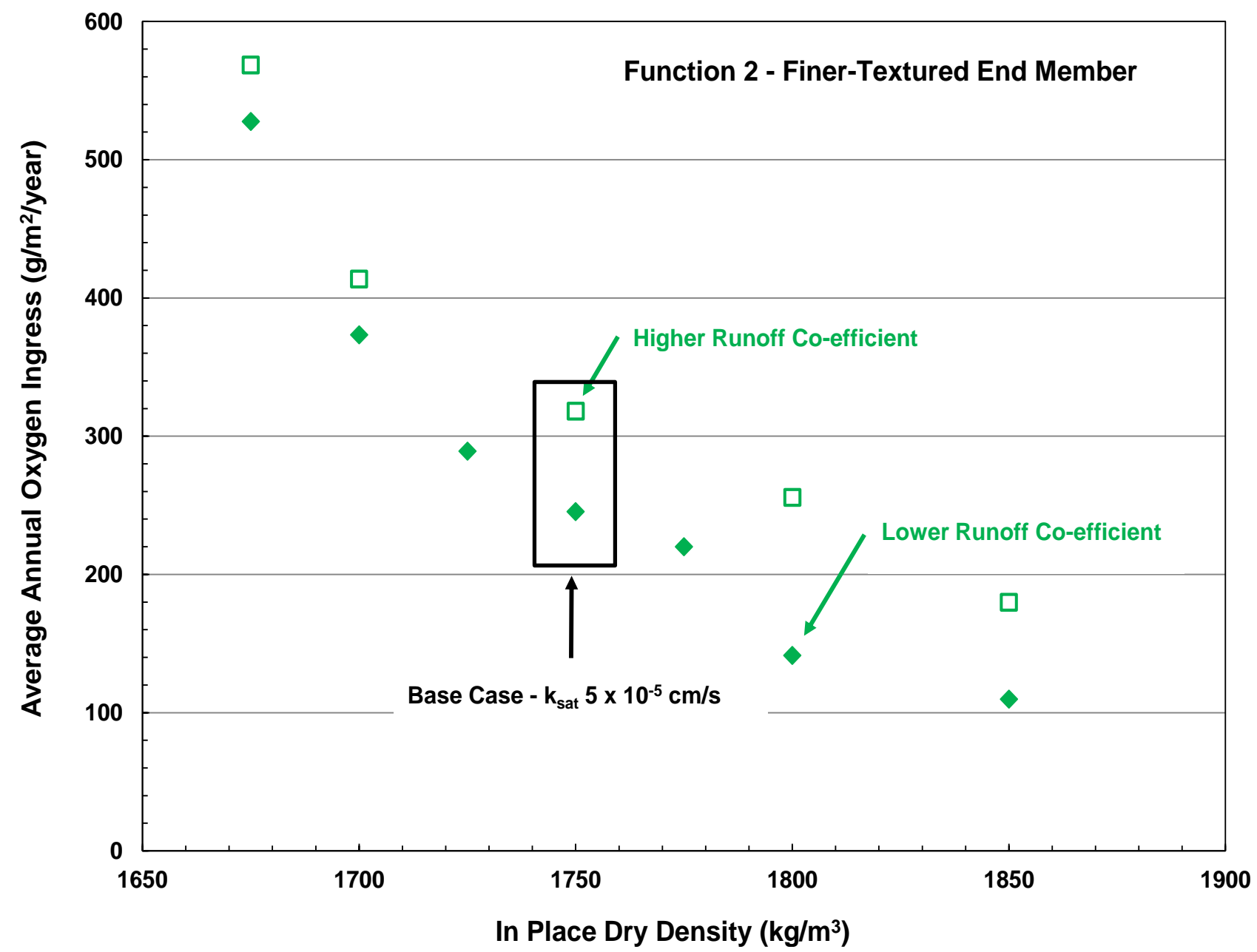

Figure 5 Results of modelling to determine optimum specification for materials placement

The objective of the numerical modelling program was to develop guidelines for progressive placement and encapsulation of PAF. It is anticipated that an easy to measure metric, such as in place dry density, would be required in the field to guide materials placement. Figure 5 provides a comparison of the anticipated performance of the ROM materials over a range of anticipated in place field dry density. 
The numerical modelling program examined oxygen transport by diffusion as well as transport through dissolved oxygen in net percolation. Oxygen ingress was shown to be substantially decreased by the presence of the internal sealing layers. Oxygen ingress varied greatly for the material depending on the texture of the material, its water retention characteristics (determined by $k_{\text {sat, }}$ porosity, and air entry value), and the assumed in-place dry density. Figure 5 provides the results of the simulations. The materials assessed were at the finer-textured end member of the particle size distribution (PSD) envelope.

The clear trend from Figure 5 is that with increased in place density a decrease in oxygen ingress results. However, the result is not simply a result of increased density. Additional compactive effort produces increased density leading to decreased porosity, increased air entry value and water retention, and a decreased $k_{\text {sat }}$. All of these factors lead to an increase in the degree of water retention of the encapsulation system materials and decreased oxygen ingress rates.

\subsection{Convective airflow modelling}

Density dependent convective airflow is a well-documented process, and has been observed in waste rock piles (Lu 2001). Convective airflow is initiated when a temperature induced density gradient exists between air within waste rock piles and ambient conditions. The basic principle guiding convective airflow analyses is that lower density, cooler air, will replace higher density, warmer air.

The presence of a convective cycle is heavily influenced by the following parameters (Ball \& Schjønning 2002):

- In situ moisture conditions.

- Air temperature within matrix of stored waste rock.

- Ambient air temperature.

- Material characteristics (texture and structure).

The adjective airflow through the TSF embankment was assessed using numerical modelling. This entailed the use of three numerical models (TEMP/W, AIR/W, and SEEP/W) coupled within the GeoStudio software suite. Surface infiltration seepage rates were calculated using VADOSE/W.

The climate conditions assigned to the numerical model took into account the climate database developed for the Martabe site. The numerical model assigned a constant surface flux rate based on net percolation results (Section 3.1).

The thermal conditions assigned to the numerical model result in a temperature gradient from within the embankment to the ambient atmosphere. The internal waste temperature of the numerical model was set to a constant $25^{\circ} \mathrm{C}$. The ambient atmospheric temperature was varied on a monthly basis based on the climate database at site.

The temperature gradient results in the development of convective airflow cycles within the waste rock storage facility (WRSF). The convective cycles within the WRSF can be seen by the velocity vectors (indicated by arrows) shown in Figure 6 for the base case (Function 1 material, $\mathrm{k}_{\mathrm{sat}}=5 \times 10^{-5} \mathrm{~cm} / \mathrm{s}$ ). The points $1-6$ shown on the crest of the structure are shown as simulation datapoints in Figure 7. 


\section{6}

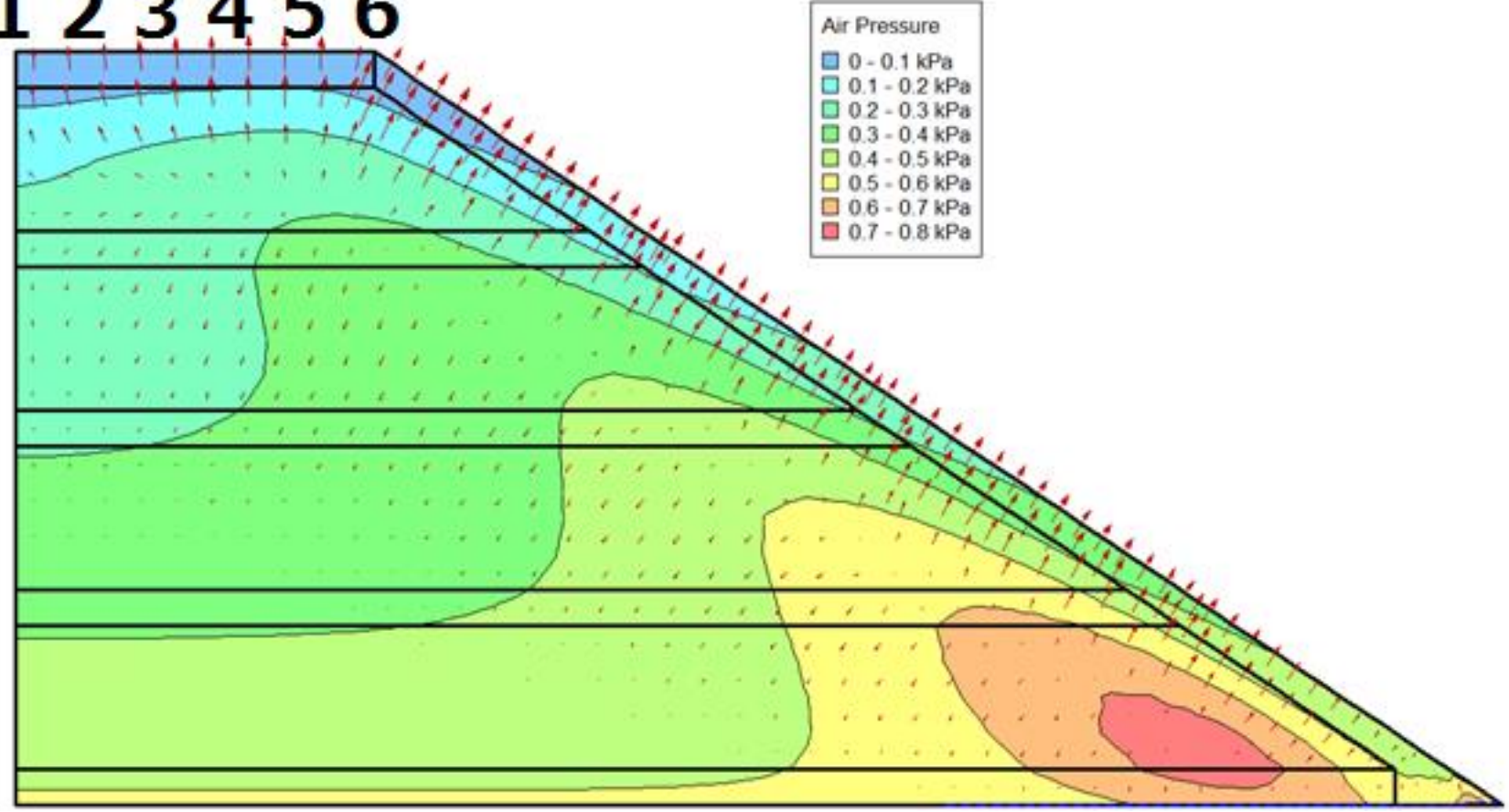

Figure 6 Airflow vectors for the base case simulation

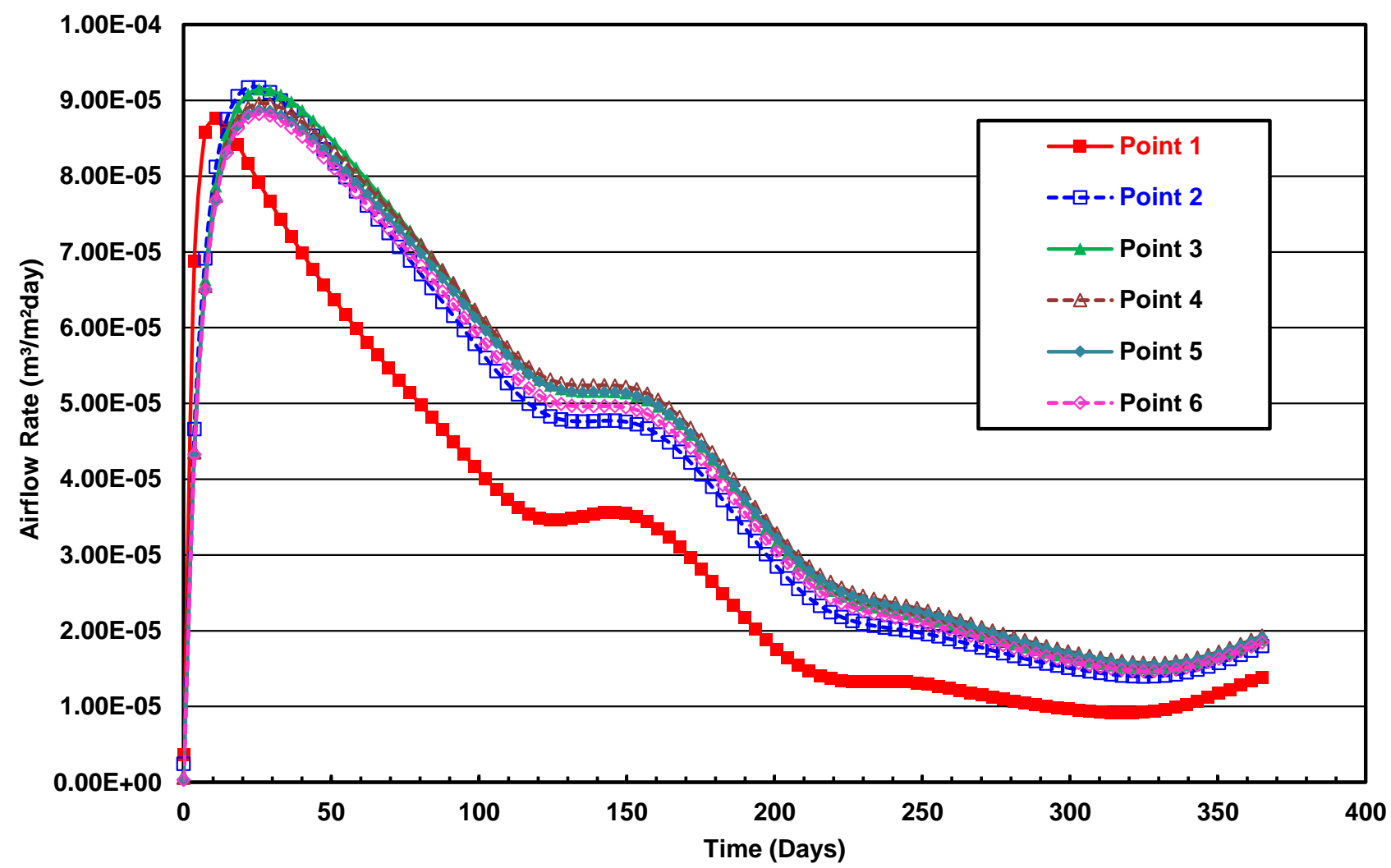

Figure 7 Airflow rates across top of Martabe WRD at the end of one year of model simulation

Airflow rates across the top of the WRD at the end of one year of model simulation are shown in Figure 7. The peak airflow rate of $9 \times 10^{-5} \mathrm{~m}^{3} / \mathrm{m}^{2} /$ day corresponds to approximately $40 \mathrm{~g} / \mathrm{m}^{2} / \mathrm{yr}$. This airflow rate is substantially lower than that calculated via diffusive processes and is not a substantial source of airflow into the deposit. 
The relative decrease in airflow through the deposit are a result of the wetting up of the embankment due to infiltration of meteoric waters at the surface restricting airflow. As long as the saturation of the sealing layers is maintained, it is not likely that advective airflow processes will be a substantial source of oxygen for oxidation processes.

The results of the analytical model illustrate that oxygen ingress due to thermal convection cells is anticipated to be low, even with elevated internal WRSF temperature and low degree of saturation conditions. For the base case simulation, oxygen ingress by convection is not significant compared to the values predicted for oxygen ingress by diffusion. Advective airflow rates through convective processes will be minimised if materials and placement practices during the construction of the TSF embankment are sufficient to produce the expected degree of saturation and provide an airflow barrier. This statement holds true even for the worst case scenario of the entire embankment being unsaturated with a low degree of saturation.

Placement of materials close to the edges of the structure, i.e. near exposed slopes, was considered based on additional modelling. The results of this additional modelling suggests the placement of high grade sulphide sulphur near the outlying slopes of the landform should be minimised. If sufficient materials are available, consideration should be given to increasing the thickness of the sealing layers in these locations or placement of a buffer layer of NAF materials to provide increased oxygen diffusion lengths from surface to the underlying PAF material.

\section{$4 \quad$ Waste placement specifications}

Results from the numerical modelling program were used to derive waste material placement specification encompassing the range of potential waste and sealing materials. Based on modelling results, the objective is to strategically place finer-textured material as engineered sealing layers to create contained segments of PAF material. This will significantly control and reduce oxygen availability to the PAF material during and following construction.

The material placement specifications address both the texture and placement density of the sealing cover materials. Note however, that this framework then correlates to the key hydraulic material characteristics for these sealing cover layers; namely, sufficient moisture retention and reduced water (and air) permeability.

The selected waste placement configuration is shown in Figures 8 and 9. This entails $8 \mathrm{~m}$ lifts of PAF with $2 \mathrm{~m}$ of compacted finer textured material placed on the front face, surface and back wall of PAF material to form sealing layers.

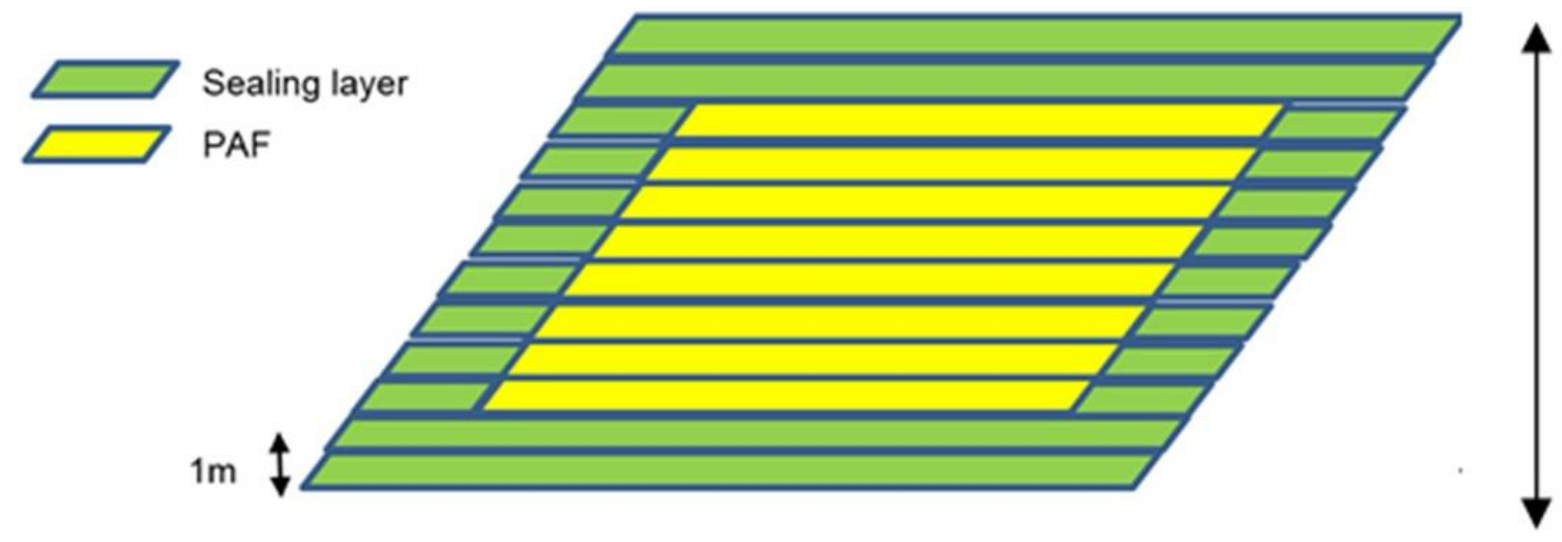

Figure 8 Internal structure of a rock cell 


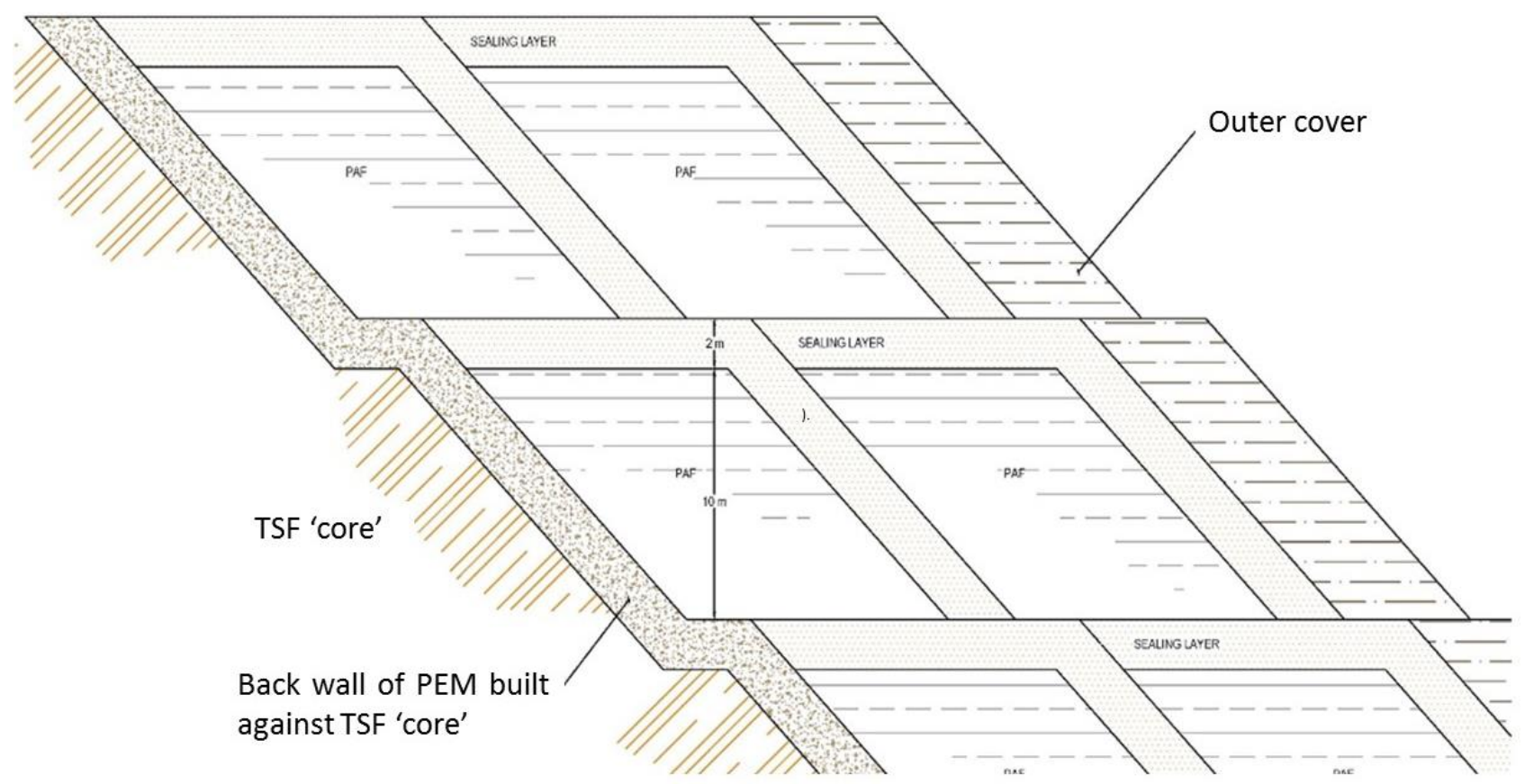

Figure 9 Cross-section showing stacked nature of progressive encapsulation method (PEM) segments

The required water retention characteristics of the sealing layer materials are correlated to in situ dry density and $k_{\text {sat }}$ values based on the texture of the potential cover material, and is determined from modelling within VADOSE. The values are based on the PSD of the material and, in particular, the percent passing a \#200 sieve ( $0.074 \mathrm{~mm}$ - silt and clay content), and the \#4 sieve ( $4.75 \mathrm{~mm}$ - sand content). For each range of PSD, a minimum permissible dry density and maximum permissible $k_{\text {sat }}$ value are given to produce a cover system that will limit oxygen ingress to a lowest reasonable value. Both target values must be achieved to achieve the predicted performance.

Based on the results of the numerical modelling program, the target oxygen ingress value of the sealing layer was determined to be $<200 \mathrm{~g} / \mathrm{m}^{2} /$ year. This correlates to approximately $6 \mathrm{~mol} / \mathrm{m}^{2} / \mathrm{yr}$ of oxygen. It is accepted, within the mining industry, that a $1 \mathrm{~m}$ water cover over PAF material correlates to approximately $1 \mathrm{~mol} / \mathrm{m}^{2} / \mathrm{yr}$ of oxygen. Hence, the target adopted for the Martabe site is within an order of magnitude of a typical water cover. This is judged to be a reasonable and defensible target.

The design provides scope for multiple cells to be placed front to back through any given lift of the embankment.

The TSF embankment is constructed using $1 \mathrm{~m}$ rolled layers (Figure 8), and a photograph of a rolled surface is shown in Figure 10. Progressive compaction of each lift of overburden as the embankment is constructed will minimise the amount of oxygen and water ingress into the structure. This is achieved in the initial instance by a dozer pushing out the paddock dumped overburden, and the dump trucks bringing in overburden are expected to provide significant compaction of each lift. Rolling using a mechanised roller of surfaces at $1 \mathrm{~m}$ intervals will provide the secondary and most significant level of compaction. 

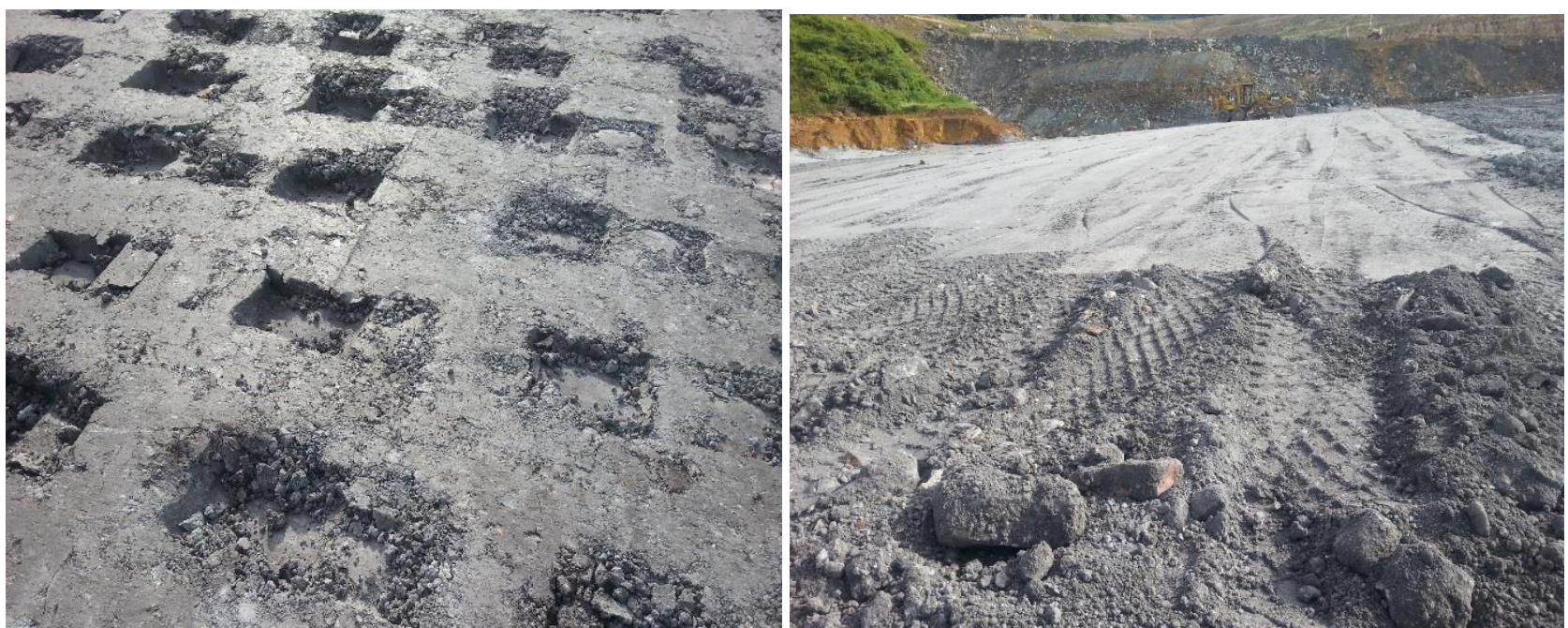

Figure 10 Site compaction on ROM material achieved using a roller. Note what appear to be large rock fragments are clumps of clay breccia which are readily broken down by compaction

For the sealing layers an engineering specification has been set based on the texture (PSD) of the material and the dry density which is an indication of the degree of compaction required. The specification is based on the results of oxygen ingress modelling. This compaction will significantly reduce the amount of oxygen and water ingress to the placed overburden. In addition, the benefits of paddock dumping and compaction also means there is less potential for significant differential settlement of the TSF embankment compared to end tipping, which is important for the construction of the sealing layers.

\section{$5 \quad$ Monitoring}

OKC has developed a detailed monitoring system design for the Martabe TSF embankment entailing use of several instrument types. Details of the monitoring system for the sealing layer can be seen in Figure 11 which is a schematic of the installation. Instruments include galvanic oxygen sensors, matric potential sensors, volumetric water content probes and vibrating wire piezometers. The monitoring system is designed to be lifted during construction so that sensors installed in early lifts can be continued to be monitored during future construction. 


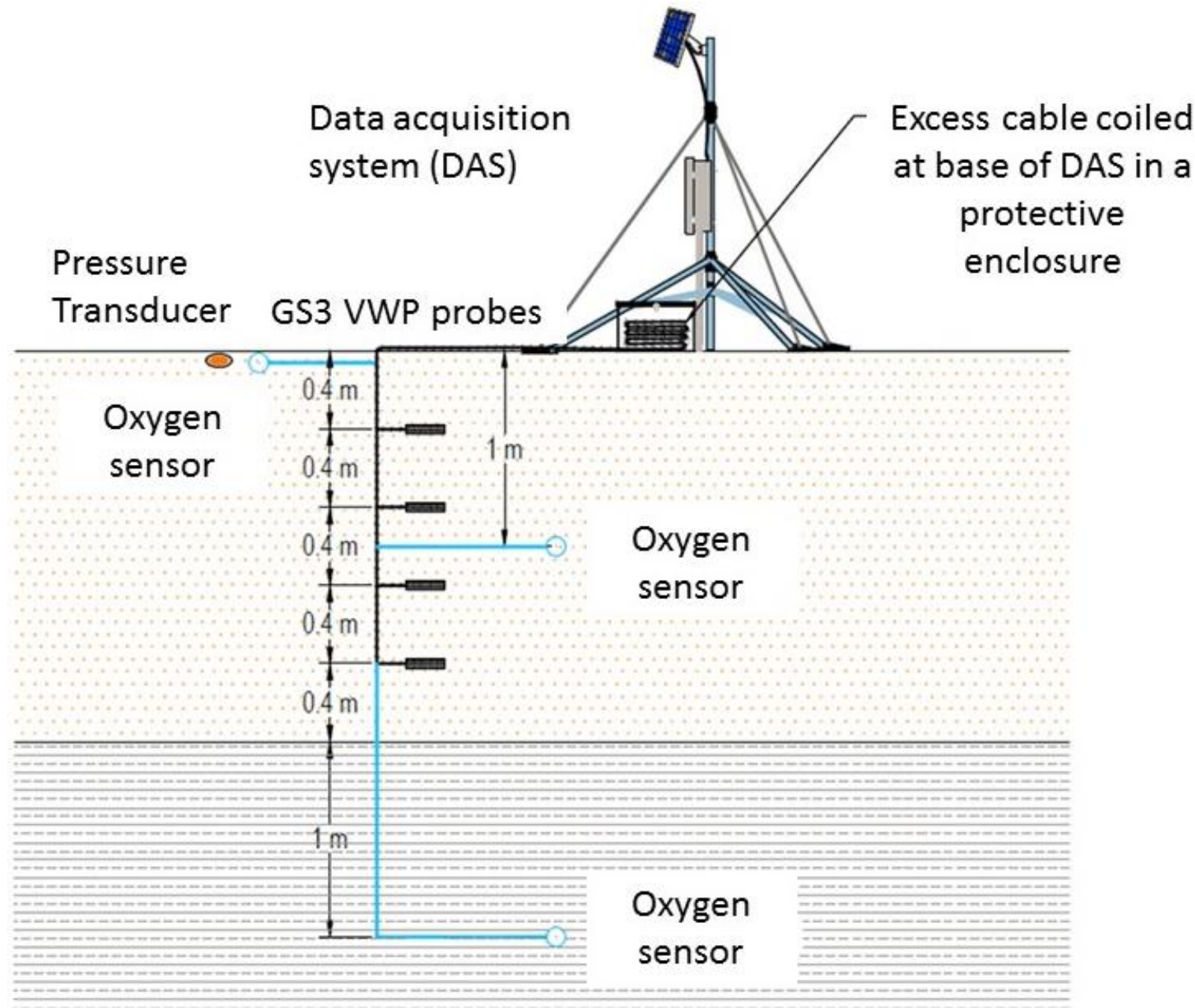

Figure 11 Monitoring installation detail

\section{Conclusion}

A progressive waste rock sealing strategy has been shown to be a feasible option at the Martabe Gold Mine for the control of AMD. It has also proven compatible with geotechnical outcomes required for construction of a TSF embankment. In addition to the predicted good performance of the system in controlling oxygen entry, this strategy offers a number of significant benefits compared with approaches that rely on a final cover system for AMD management:

- The progressive encapsulation of PAF provides for a higher factor of engineering safety in design, as the internal sealing layers act to isolate PAF material within multiple encapsulated segments.

- There is much less reliance on the performance and ongoing integrity of the outermost sealing layer.

- The risk of insufficient sealing material being available at mine closure is mitigated.

- PAF material is exposed to oxygen for only relatively short periods of time before being encapsulated. This assists in operational water management including the cost of treatment of runoff water.

- Sealing specifications can be tested and improved during operation of the mine.

- Installation of a monitoring system is feasible and will provide validation data to quantify both oxygen ingress and net percolation which can be used to calibrate models and refine predictions of potential closure risks. 
The development of a detailed LOM waste rock management strategy has facilitated the adoption and buy in of the progressive encapsulation method by site teams as the practicality of the strategy can be demonstrated. A key learning from the development of this strategy is that planning must involve all key site geology and mining teams. The practical success of implementing such strategies depends to a great extent on a planned and connected flow of data right through the mine planning spectrum from waste block modelling, through scheduling, mining, design and build, validation and monitoring. The approach is therefore best described as an integrated waste management process.

\section{References}

Ball, BC, \& Schjønning, P 2002, Methods of Soil Analysis, Part 4, Soil Science Society of America, pp. 1141-1158.

Harries, J 1997, 'Acid mine drainage in Australia: Its extent and potential future liability', Supervising Scientist Report 125, Supervising Scientist, Canberra, p. 94.

Lottermoser, BG 2003, Mine wastes: Characterization, treatment and environmental impacts, Springer-Verlag, Berlin, p. 277.

Lu, N 2001, 'An analytical assessment on the impact of covers on the onset of air convection in mine wastes', Numerical and Analytical Methods in Geomechanics, August 1999, pp. 347-364.

Pearce, SR 2014, 'Beyond the PAF Cell', in H Miller and L Preuss (eds), Proceedings of the Eighth Australian Workshop on Acid and Metalliferous Drainage, pp 97-110.

Pearce, SR 2015, 'A risk-based approach using process flow diagrams for operational waste rock classification - case studies', in AB Fourie and M Tibbett (eds), Proceedings of the Eleventh International Conference on Mine Closure, in press, Australian Centre for Geomechanics, Perth.

Pearce, SR, Beavis, FR, Winchester, SJ \& Thompson H 2012, 'Managing closure risks by integrating acid and metalliferous drainage assessments with mine scheduling - real world applications', in AB Fourie \& M Tibbett (eds), Mine Closure 2012 Proceedings of the Seventh International Conference on Mine Closure, Australian Centre for Geomechanics, Perth, pp. 801-814. 